\title{
CDISC SDTM Genetic Sample Type Terminology
}

National Cancer Institute

\section{Source}

National Cancer Institute. CDISC SDTM Genetic Sample Type Terminology. NCI

Thesaurus. Code C111114.

Terminology associated with the genetic sample type codelist of the Clinical Data

Interchange Standards Consortium (CDISC) Standard Data Tabulation Model (SDT M). 